\title{
COMPUTING THE LOCATION AND THE DIRECTION OF BIFURCATION FOR SIGN CHANGING SOLUTIONS
}

\author{
PHILIP KORMAN AND YI LI
}

Abstract. We consider sign-changing solutions of the Dirichlet problem

$$
u^{\prime \prime}+\lambda f(u)=0,0<x<1, u(0)=u(1)=0,
$$

with $n \geqslant 0$ interior roots. We give a necessary and sufficient condition that a turn occurs at the solution $(\lambda, u(x))$, depending only on the maximum value of the solution $u(x)$. If a turn does occur, we give another formula allowing to compute the direction of the turn. Our results generalize those in P. Korman, Y. Li and T. Ouyang [6], where positive solutions were considered. We give similar results for Neumann problem.

Mathematics subject classification (2010): 34B15.

Keywords and phrases: computing the location and the direction of bifurcation, curves of sign-changing solutions.

\section{REFERENCES}

[1] M. G. Crandall And P. H. Rabinowitz, Bifurcation, perturbation of simple eigenvalues and linearized stability, Arch. Rational Mech. Anal., 52 (1973), 161-180.

[2] P. Korman, The global solution set for a class of semilinear problems, J. Math. Anal. Appl., 226, 1 (1998), 101-120.

[3] P. Korman, Global solution branches and exact multiplicity of solutions for two point boundary value problems, Handbook of Differential Equations, Ordinary Differential Equations, 3, Edited by A. Canada, P. Drabek and A. Fonda, Elsevier Science, North Holland, (2006), 547-606.

[4] P. Korman, A global approach to ground state solutions, Electron. J. Differential Equations, 2008, $122,(2008), 1-13$.

[5] P. Korman, Y. Li AND T. OUYANG, Exact multiplicity results for boundary-value problems with nonlinearities generalising cubic, Proc. Royal Soc. Edinburgh, Ser. A, 126A (1996), 599-616.

[6] P. Korman, Y. Li And T. OuYAng, Computing the location and the direction of bifurcation, Mathematical Research Letters, 12 (2005), 933-944.

[7] R. SCHAAF, Global behaviour of solution branches for some Neumann problems depending on one or several parameters, J. Reine Angew. Math., 346 (1984), 1-31.

[8] R. SchaAf, Global Solution Branches of Two Point Boundary Value Problems, Lecture Notes in Mathematics, 1458, Springer-Verlag, 1990.

[9] S.-H. WANG, On S-shaped bifurcation curves, Nonlinear Anal. TMA, 22, 12 (1994), 1475-1485. 